\title{
Processos Criativos: recorte e colagem como vetores de experiência para a elaboração de novas paisagens
}

Margarete Sacht Góes ${ }^{1}$

Felipe Lacerda²

Recebido em: 13/04/2020

Aprovado em: 19/05/2020

DOI: $10.5965 / 23580925242020128$

\footnotetext{
1 Doutora em Educação pela Universidade Federal do Espírito Santo (UFES). Professora da Universidade Federal do Espírito Santo (UFES). E-mail: magsacht@gmail.com

2 Graduando em Artes Visuais pela Universidade Federal do Espírito Santo (UFES). E-mail: felipelacerda02@gmail.com
} 


\section{RESUMO}

Este artigo objetiva analisar o processo de criação de crianças de quatro anos de idade, ao utilizarem a técnica do recorte e colagem, perfazendo uma análise comparativa do processo quando monitorado diretamente pelo professor e quando deixado acessível para as crianças criarem e imaginarem. Por meio de recortes e da técnica da colagem, descobrem novas imagens/paisagens a partir da técnica produzida com fragmentos de imagens retiradas de mídias impressas e da memória afetiva que atravessa e constitui as crianças. Fundamenta teoricamente os estudos em Vigotski (2009), Cunha (2018) e lavelberg (2008), para discutir o ensino da Arte para crianças. Finaliza destacando as diferentes ações que contribuem para os processos de criação para as crianças da Educação Infantil.

Palavras-chave: artes visuais, processo de criação, educação infantil.

\section{ABSTRACT}

This article aims to analyze the process of raising four-year-old children using the technique of clipping and collage, making a comparative analysis of the process when directly monitored by the teacher and when made accessible to children. create and imagine. Through clippings and the collage technique, they discover new images / landscapes from the technique produced with fragments of images taken from press media and the affective memory that crosses and constitutes the children. It theoretically bases the studies in Vigotski (2009), Cunha (2018) and lavelberg (2008), to discuss the teaching of Art to children. It concludes by highlighting the different actions that contribute to the rearing processes for children in kindergarten. 
Keywords: visual arts, creation process, child education.

\section{INTRODUÇÃO}

Compreender como ocorrem os processos de criação das crianças da Educação Infantil, ao propormos atividades de Artes Visuais, ainda tem sido um grande desafio, pois esses processos nos provocam a pensar a dimensão da criatividade e da imaginação.

A criatividade é uma das dimensões constitutivas da infância e ela indica as singularidades e idiossincrasias de cada criança. Para Vigotski (2009, p. 11), a imaginação é a base de "[...] toda actividade criadora, manifesta-se igualmente em todos os aspectos da vida cultural, possibilitando a criação artística, científica e técnica".

Ao refletirem sobre a necessidade das escolas se abrirem para novas possibilidades, Dhalberg, Moss, Pence (2003, p. 7778) inferem que elas necessitam proporcionar às crianças "[...] oportunidades de usar a sua criatividade para experimentar e assumir responsabilidades, realizar escolhas com relação a sua vida e ao seu futuro". Ostetto (2011) infere que:

[...] para contribuir com os processos expressivos, além de alargar as oportunidades de acesso à riqueza da produção humana, promovendo a aproximação aos diferentes códigos estéticos, é preciso também promover encontros e buscas, encorajando as crianças à experimentação. Afinal, para construir, dar forma, inventar, compor, produzir com diferentes materiais é fundamental conhecer e conquistar certa intimidade com esses materiais (OSTETTO, 2011, p. 06).

Nesse sentido, para estimular a imaginação e encorajar as crianças à experimentação, é preciso ajudá-las a fazer com que, ao utilizarem materiais comuns, do cotidiano escolar, elas se expressem criativamente. É incentivá-las a "ver" para além do comum, ou seja, para o incomum, para o que não é acessível ao olhar de todos. Outro ponto importante que destacamos é exa- 
tamente a intimidade com os diferentes materiais que são colocados à disposição das crianças ao elaborarem suas produções.

Nossa busca então se inicia no olhar minucioso do processo criativo de crianças de 04 anos de idade, de um Centro de Educação Infantil, cuja turma era composta por 23 crianças, a partir de atividades corriqueiras, que são o recorte e a colagem.

Nosso objetivo era levar as crianças a fazerem um recorte visual dos objetos e da vida, daquilo que cabe no seu mundo singular e também de acessarem materiais que deveriam estar à disposição delas, pois o que observávamos era um cerceamento em relação aos usos de materiais e mais especificamente nessa proposta, a cola e a tesoura que, geralmente, são utilizados pela professora, o que deixa a criança apenas como observadora do processo.

O questionamento que fazemos então é exatamente por que não deixar que as crianças experimentem esses materiais? Por que era o professor que precisava recortar e passar a cola? Por que não ensinar para a criança os procedimentos e cuidados que se deve ter ao utilizar esses materiais? Esse controle exacerbado interrompe ou inibe o processo criativo? É nesse contexto que buscamos mudar a dinâmica do que estava posto como regra, a partir do momento que começamos a ouvir o que as crianças tinham a nos dizer sobre essas questões e, por meio das narrativas delas, era notável o desejo de fazerem uso desses materiais, pois muitas já faziam uso deles em suas casas. Assim, na técnica da colagem, buscamos subsídios para percorrermos juntamente com as crianças o processo de criação de cada uma ao terem acesso a materiais que, inicialmente, só eram acessíveis aos professores.

Nessa perspectiva, o objetivo deste artigo é analisar o processo de criação de crianças de 04 anos de idade, ao utilizarem a técnica do recorte e colagem, perfazendo uma análise comparativa do processo quando monitorado diretamente pelo professor e quando deixado acessível para as crianças criarem e imaginarem.

Então, fundamentamos este estudo a partir da perspectiva histórico-cultural e da cultura visual, ao pensarmos esses sujei- 
tos inseridos em contextos historicamente produzidos e cotidianamente atravessados pela proliferação e penetração das imagens em suas vidas.

\section{A CONSTITUIÇÃO DOS REPERTÓRIOS IN- FANTIS}

Ao pensarmos a criança a partir da perspectiva histórico-cultural, compreendemos que ela, nos processos de aprendizagem e desenvolvimento, traz consigo uma gama de processos criativos, que permitem que ela elabore e crie desenhos, pinturas e colagens, dentre outras linguagens a que tem interesse.

A produção dessas atividades também é constituída pela influência dos adultos que a cercam, ou seja, o universo infantil é constantemente atravessado pelos desenhos animados, filmes, músicas e teatro, que compõem e ampliam o repertório visual das crianças. Ao pesquisar sobre a imaginação na infância, Ladislau (2018) destaca que:

[...] acreditamos que, quanto mais vivências, experiências e percepções são proporcionadas à criança, mais ela se permite fantasiar, criar e, de alguma forma, expressar sua imaginação, seja por meio da dança, da música, das artes visuais, da brincadeira, da literatura ou de práticas artísticas (LADISLAU, 2018, p. 12).

Partindo dessa consideração, somos levados a refletir que nem todas as crianças têm acesso diário a espaços culturais, como museus, galerias, teatro dentre outros. Muitas delas acabam tendo esse contato, de forma muito rápida e breve, quando ainda estão transitando pela educação básica. Grosso modo, essa responsabilidade cabe, quase que exclusivamente, à escola, que muitas das vezes é o único meio de conhecer e acessar esses locais.

Apresentar aparatos para que as crianças possam desenvolver o seu lado artístico e criativo, sua própria poética, é uma ação primordial durante a infância, pois é nesse momento que elas começam a tomar gosto pelo ato de criar, de inventar. Im- 
portante, então, mostrar diferentes modos de brincar, criar, inventar e também de apresentar novos modos de como desenhar, pintar, fazer esculturas, recortar e colar, produzir papel artesanal, criar brinquedos e brincadeiras, dando liberdade para que escolham os materiais e as formas de se expressarem criativamente.

Essa discussão nos aproxima de outra que é a polêmica quando tratamos do "diálogo entre a produção artística da criança e a arte adulta" (IAVELBERG, 2008, p. 1426), pois há uma oposição entre "arte-educadores modernos e tradicionais" que se dividem entre a Escola Nova (fundamentada em fatores endógenos) e a Escola Tradicional (fundamentada em fatores exógenos). Assim, nas ações pedagógicas, o acesso à produção de arte dos adultos era muitas vezes negado, pois se considerava que as produções adultas exerceriam uma influência negativa na criatividade das crianças. Destarte, "[...] as interações das crianças com a arte adulta como fonte para suas criações permanecem excluídas das idéias dos autores de educação até o final da segunda metade do século 20, mais precisamente até a década de 80" (IAVELBERG, 2008, p. 1426). A partir daí, abre-se uma discussão entre os Arte/Educadores que passam a admitir que as crianças se apropriam e ressignificam a estética adulta em suas produções.

Segundo lavelberg (2008), em relação à perspectiva dos Arte/Educadores modernistas e a contemporâneos existe um aspecto importante que os diferencia. Sobre essa problemática, a autora detalha que:

Essa linha se contrapõe às análises dos arte-educadores contemporâneos, que observam as visualidades das produções infantis em suas transformações históricas - possíveis pela documentação escrita e visual da arte infantil ora existente -, considerando a influência exercida nas criações da infância pelas visualidades do meio, ou seja, pelos códigos da linguagem da arte e da cultura visual, e os fatores exógenos, sem desprezar os fatores endógenos (IAVELBERG, 2008, p. 1426-1427).

Essa percepção da autora vai ao encontro de nossas obser- 
vações, pois ainda hoje é possível perceber no ensino de arte - na prática de alguns educadores - uma insistência no método de reprodução de obras de artistas, a qual afirmam ser releitura. Entretanto, o que ocorre dentro das escolas é que a "releitura" passou a ser tratada como "cópia" ou seja, a reprodução fiel das obras dos artistas. Barbosa (2005, p. 144-145) afirma que "[...] os resultados são trabalhos em que o aluno tenta agradar o professor copiando a obra ou o proprio professor acha que o melhor resultado é o que se encontra mais próximo representacionalmente da obra em questão".

Ressaltamos aqui o fato de se apresentar às crianças bons referenciais da produção artístico-cultural para a ampliação do repertório visual, mas é importante compreender que, a depender da maneira como eles são explorados com as crianças, mudaremos toda a forma de apropriação dos elementos estéticos-visuais.

Reconhecemos a importância desse referencial, mas, é preciso pensar em como elaborar os objetivos a serem alcançados a partir do que se mostra e propõe. Ostetto (2007, p. 02-03) nos convoca a pensar as atividades de arte na Educação Infantil a partir de algumas perguntas como: “[...] Estaria a arte presente nessas práticas? Qual o sentido de tais atividades? Quem está em evidência nas propostas [...] o produto ou o produtor; a atividade ou aquele que a realiza?".

Nesse contexto de indagações de como o ensino da arte tem se constituído para as crianças da Educação Infantil, é preciso pensar e repensar questões que estão diretamente voltadas para os processos de criação. O diálogo, no qual as crianças estão inseridas, é potente ao pensarmos outros territórios para além dos muros das escolas, o que nos leva a questionar sobre quais práticas cotidianas os aprendizes vivenciam fora desse território, como dialogar com esses atravessamentos e afetos que vão interferir diretamente em suas produções e quais são as bagagens que esses aprendizes trazem com eles/as para sala de atividades.

Essas perguntas tornam a educação palpável, materializada a partir de sujeitos concretos e não idealizados, que pro- 
duzem sentidos a partir do que se vive, do que se experiencia. Podemos ir além com essas provocações ao pensarmos a desterritorialização da arte para as crianças pequenas, ou seja, é preciso derrubar as paredes das salas de atividades e ampliar os espaços de experimentações e vivências.

\section{POR UMA METODOLOGIA EM QUE AS CRI- ANÇAS ENTREM EM CENA}

Para dar conta do nosso objetivo, que era analisar o processo de criação de crianças de 04 anos de idade, ao utilizarem a técnica do recorte e colagem, perfazendo uma análise comparativa do processo quando monitorado diretamente pelo professor e quando deixado acessível para as crianças criarem e imaginarem.

A pesquisa se deu durante as aulas de estágio supervisionado em Arte na Educação Infantil e, inicialmente, observamos que as propostas metodológicas utilizadas eram permeadas por atividades que iam desde recorte e colagens, a pinturas e desenhos, que eram sempre acompanhados de um tema em que a turma estava desenvolvendo. Sempre com uma boa roda de conversa sobre o assunto, a rotina era envolvida por histórias, vídeos e visitas a locais externos, onde se desenvolviam diversas pesquisas e experimentações sobre o que estava sendo trabaIhado.

As atividades eram realizadas em etapas e a divisão de pequenos grupos de crianças era uma prática rotineira. Dessa forma, a professora e equipe da sala conseguia dar maior assistência durante o processo em que a criança estivesse produzindo sua atividade. Entretanto, podíamos dizer que o excesso de tutelamento também se fazia presente em muitos momentos, como por exemplo nas atividades de recorte e colagem, as quais optamos por analisar.

Destacamos nossa surpresa ao propormos para a professora que trabalharíamos com a linguagem do recorte e da colagem para podermos observar os processos de criação das crian- 
ças, pois ela nos informou que ainda não dava a tesoura na mão das crianças e nem a cola, os dois materiais eram utilizados somente pelas professoras e auxiliares. Optamos, então, por propor diferentes atividades, passando pelo processo de produção - em que os materiais eram controlados pelas professoras - até chegar ao momento em que as crianças trabalharam sozinhas constituindo, assim, seu percurso criativo a partir dos materiais a que tinham acesso.

Nessa perspectiva, no primeiro encontro, fizemos uma pequena explanação sobre o que é e como se trabalha com a colagem como uma técnica artística em que utilizamos vários materiais, que podem (ou não) variar texturas, sobreposições e também colá-las lado a lado, descobrindo e compondo novas imagens/paisagens.

A colagem como técnica tem surgimento datado da história antiga, entretanto teve seu valor artístico reconhecido a partir do século $X X$, com sua utilização no Cubismo, antes disso, era considerada ou brincadeira de criança, ou manifestação artística popular e desprovida de fundamentação crítica. De acordo com Martins:

A colagem foi desenvolvida por Braque e Picasso em torno de 1911, no final da primeira fase do cubismo, dita "analítica". Ela é justamente considerada como um dos achados mais relevantes da arte moderna e como um elemento central do cubismo. Nessa condição, a colagem é objeto de interpretações variadas (MARTINS, 2007, p. 51).

Como objeto de interpretações variadas, a colagem permite a utilização de diversos materiais sobre um suporte, como madeira, pedaços de jornal e também objetos, podendo ter um imbricamento entre pintura e escultura, o que faz dela uma técnica que põe em questão os limites de determinadas técnicas.

$\mathrm{Na}$ arte Moderna, a técnica da colagem passa a ser empregada em diversos movimentos artísticos e escolas artísticas, promovendo sentidos muito variados. A utilização de materiais muito diferentes de papéis cria uma nova gama de possibilida- 
des de produtos artísticos.

Entretanto, não apenas as críticas ao momento vivido foram temas utilizados na colagem, mas também faces e imagens abstratas figuraram muitas obras. A expressividade conseguida com a colagem é única e distante de todas as outras texturas. Isso levou os artistas a produzirem uma grande quantidade de produtos muito diferentes entre si, garantindo uma pluralidade artística muito rica e profunda.

Esse contexto histórico é necessário para compor o repertório artístico cultural para a equipe de professores, haja vista que não havia, nesse Centro de Educação Infantil, um professor licenciado em Arte. Nesse sentido, nos remetemos a Martins e Picosque (2012, p. 36), quando elas citam que a nutrição estética "[...] é um modo de gerar o abastecimentos dos sentidos".

Após a apresentação do trabalho de um dos autores que têm a colagem como referência para a constituição da sua poética pessoal, e contando sobre o processo artístico de criação, as crianças puderam tocar nas imagens, observá-las, fazer perguntas e dialogar sobre o que viam e o que sentiam.

Ao apresentarmos os trabalhos, algumas crianças, de forma livre, escolheram uma obra para realizar uma "leitura de imagem" (Figura 1) acerca do que se observava na colagem. Elas destacaram detalhes que mais chamavam a atenção, levando em conta o repertório de imagens que já tinham a partir do que viam e experienciavam no mundo da cultura adulta e no seu universo infantil. Retomamos então a reflexão de lavelberg (2008), quando ela cita que

O diálogo entre a produção artística da criança e a arte adulta remete à polêmica que opõe arte-educadores modernos e tradicionais, divididos por uma fronteira que situa, de um lado, a Escola Nova, com destaque nos aspectos endógenos da aprendizagem (desenvolvimento da criança, sensibilidade, mundo interno, motivação, emoções, auto-expressão) e, de outro, a Escola Tradicional, que sublinha os aspectos exógenos da aprendizagem (cânones, valores culturais, informações do universo da arte, saberes técnicos, história da arte) (IAVELBERG, 2008, p. 1426-1427). 
Nesse contexto, defendemos a ideia de que, numa perspectiva contemporânea de se trabalhar arte com as crianças, é preciso pensar na Arte em diálogo constante com a vida. Não dá para dicotomizar e, nesse sentido, a produção artística adulta contribui para a constituição das identidades e da produção artística infantil.



Figura 1: Leitura das obras

Fonte: Acervo pessoal (2019)

Refletindo com as crianças sobre a produção, mostramos que as imagens podiam ser alteradas ao colarmos uma sobre a outra. Assim questionamos se elas sabiam que outro material nós poderíamos utilizar para mudar uma imagem. A resposta foi imediata: "[...] a gente pode pintar!" (Mat.). E se tivermos duas imagens? "[...] com duas a gente pode recortar papel colorido pequeno e colar" (Isa.).

Nesse momento de fruição, as crianças sugeriram novos títulos a partir de análises individuais, mas que no processo, passaram a ser coletivas. Sobre a leitura de imagem, Kehrwald (2006) destaca que:

[...] é preciso levar em conta que as obras de arte nos remetem, muitas vezes, a objetos já vistos, a formas ou fatos do cotidiano e passamos a identificar aspectos comuns entre os mesmos. Essas 
nuanças passam despercebidas a um olhar desacostumado. No entanto, um olhar educado para ver [...] perceberá as semelhanças e diferenças, fará analogias e, por consequência, identificará as inter-relações, isto é, o intertexto (KEHRWALD, 2006, p. 28-29).

Nosso objetivo era sensibilizar o olhar das crianças para o que, costumeiramente, não vemos, não observamos. Na sequência então, realizamos uma atividade individual de colagem utilizando apenas três imagens de meios impressos como revistas, jornais e cartazes de filmes, para criar sua composição, as quais foram recortadas pelos professores e entregues às crianças, em um processo de total controle de quantidade e de acessibilidade, fazendo com que cada criança escolhesse as figuras de modo aleatório.

Além do controle pré-determinado ao oferecermos as figuras/imagens já recortadas e em número controlado (no máximo duas e o restante deveria ser feito com papel recortado previamente também), a cola era utilizada apenas pelos adultos. Passávamos cola na figura e no papel e entregávamos na mão das crianças para que elas somente colassem no papel, seguindo assim, o procedimento adotado pela professora.

Entretanto, compreendemos que esse processo inibia a autonomia das crianças, pois elas ficavam esperando que nós, adultos, entregássemos em suas mãos os materiais que utilizariam em suas colagens. Além disso, percebíamos que o processo criativo também ficava comprometido, haja vista que o ato de colar se tornava mecânico, ou seja, não proporcionava reflexão, escolhas, experiências com o próprio material e interação com os amigos, o que, em nossa perspectiva, é fundamental para os processos de criação. Buscamos, então, subverter, de maneira tímida, ao propormos que as crianças rasgassem os papéis coloridos em pedaços menores e oferecendo às crianças que desejassem uma figura a mais.

Na perspectiva de irmos ao encontro das crianças, de ouvirmos o que elas tinham a nos dizer, concordamos com Cunha (2018, p. 239), quando ela propõe que “[...] É preciso observar e ouvir mais as crianças, criar laços, estabelecer diálogos e con- 
duzir o trabalho fundado nessa postura ética, respeitadora delas", assim, incentivamos também que as crianças escolhessem títulos para as produções que elas realizaram. Fomos surpreendidos por nomes criativos como "Olho tempestade" (Dan.) e "Frutas vermelhas" (Lar.) (Figuras 2 e 3).



Figura 2: Olho tempestade (Dan.) Fonte: Acervo pessoal (2019)

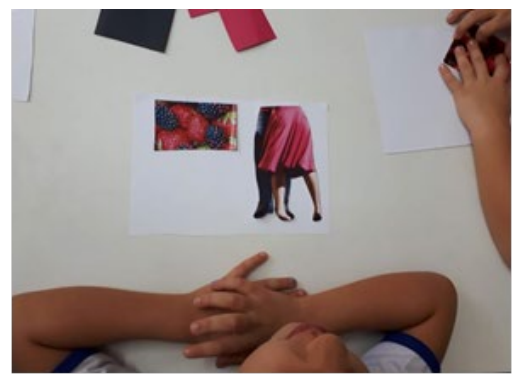

Figura 3: Frutas vermelhas (Lar.)

Fonte: Acervo pessoal (2019).

Ou seja, mesmo em situações muito direcionadas, em suas narrativas as crianças se mostravam criativas e inventivas. Importante destacar que, durante a atividade, ao conversarmos com as crianças, elas começaram a fazer experimentações voltadas para a realocação das imagens (Figura 4) sobre o papel. Elas faziam individualmente, antes da finalização do trabalho de colagem. Percebemos que isso se tornou uma constante como processo de estudos, de elaboração e reelaboração dos processos criativos e de produção de sentidos. 


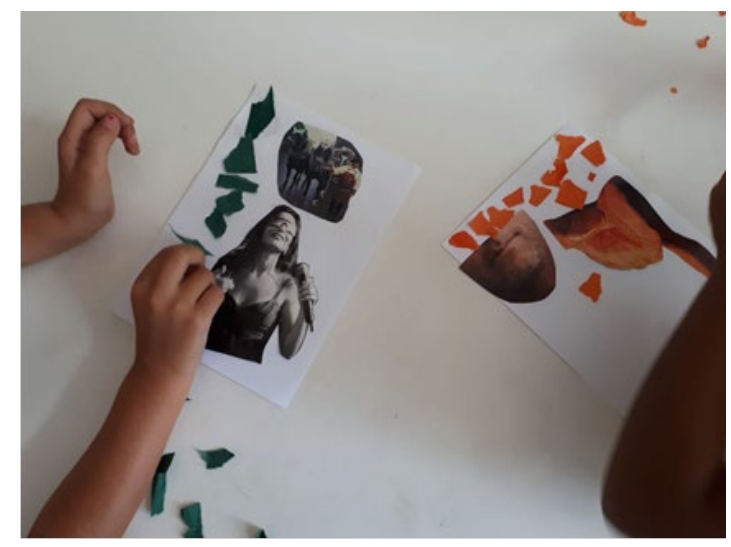

Figura 4: Experimentações e estudos de realocações de imagens Fonte: Acervo pessoal (2019).

Assim, destacamos a importância de disponibilizarmos tempo para que as crianças possam brincar com as imagens, organizá-las e mudá-las de lugar, pois é nesse momento, em que elas estão brincando e experimentando, que se constituem os processos de criação e imaginação. O resultado passa ser assim a materialização do trabalho, entretanto, o processo vivido é que produz os sentidos. É preciso deixar entrar em cena a criatividade do sujeito que está elaborando a atividade. Barbosa (2018) corrobora com esse pensamento quando infere que

O envolvimento da criança com a arte, com a experiência estética é uma das principais formas para fazer o imaginário da criança brotar, florescer. Para imergir no universo da experiência da arte, também são necessárias duas condições favoráveis ao briIhar do imaginário: tempo e paciência. Essas condições devem partir do adulto enquanto mediador de suas experiências (BARBOSA, 2018, p. 48).

Objetivando deixar as crianças irem aos poucos utilizando a cola e a tesoura, propusemos uma atividade em grupos, o que 
possibilitaria uma mediação efetiva em relação aos usos desses materiais.

Realizamos a segunda atividade em grupos de quatro crianças e, como elemento disparador, optamos pela obra intitulada "O Caracol" (1952-1953) do artista Henri Matisse (1869-1954). Essa obra é uma colagem de papéis coloridos que as crianças acessam de uma forma muito lúdica, por isso, utilizamos o livro "A arte de Matisse", de Douglas Mannering. Na roda de conversa, enquanto falávamos sobre o artista e suas obras, as crianças podiam ir observando as imagens e folheando o livro. Posteriormente, foi apresentada uma proposta em que cada grupo criaria, com papéis coloridos, um bicho/animal.

O que está em jogo aqui não é o plágio ou a cópia da obra de Matisse. A obra "O caracol" foi usada para que as crianças ampliassem o repertório relativo a produções em colagens. Então, o que nos provocava era como produziríamos uma obra coletivamente a partir da obra apresentada.

Durante a conversa refletimos sobre as diferentes maneiras para se pensar a criação de bichos com papéis coloridos e as mais variadas formas de cortar esses papéis com as mãos, criando texturas e formas irregulares, e o recorte com a tesoura. Dialogamos sobre como se usa a cola e a tesoura como instrumentos de se produzir arte, e as crianças responderam aos nossos questionamentos por meio das ações durante as atividades e, também, nos mostrando que sabiam trabalhar coletivamente.

Como resultado, a criação de bichos realizados pelos grupos a partir da atividade da obra do artista Henri Matisse (Figuras 5 a 8) inferimos que para se trabalhar com o ensino da arte na Educação Infantil torna-se fulcral repensar os usos de materiais, pois são eles que possibilitarão às crianças se apropriarem de produtos histórico-culturais produzidos pela humanidade bem como a imaginarem, criarem, se expressarem e desenvolverem suas poéticas pessoais.

Nesse sentido, reafirmamos a importância de colocarmos à disposição das crianças diferentes instrumentos, objetos, materiais e suportes, para que elas possam se relacionar com a arte de forma orgânica, experimental e processual, sem, necessaria- 
mente, produzir algo concretamente. Reiteramos que a necessidade de produção da arte materializada é um desejo do adulto e não das crianças.

Nesse processo, era preciso deixar as crianças mais livres, para que pudessem vivenciar todo o processo de criação de colagens com autonomia em relação aos materiais e, também, em relação à ideia de que é possível criar e elaborar novas imagens com as fotografias já existentes.

Assim, depois de todo repertório criado acerca da temática da colagem e seus processos de desenvolvimento, disponibilizamos revistas variadas, tesouras e colas, para que as crianças escolhessem as imagens, textos, texturas e cores que mais lhe chamavam a atenção. Ao longo da atividade, fomos passando pelas mesas e mediando os processos, dialogando com elas, mas sem interferir no processo criativo, para que as crianças elaborassem suas atividades de modo livre e orgânico, pois elas

[...] atuam a partir de um corpo que se arrisca com paixão a essas descobertas e experimentações. Essas situações, quando planejadas e conduzidas por adultos sensíveis, atentos e abertos às manifestações infantis, resultam em aprendizagens que se constroem a partir do entrelaçamento entre os interesses de investigação das crianças com os saberes das professoras, em processos nos quais as crianças são participantes de fato, com vozes que são ouvidas e consideradas nas tomadas de decisão (CUNHA, 2018, p. 237).

Nosso objetivo agora, para além de ensinar a utilizar os materiais que as crianças não tinham acesso, era observar o processo criativo, de desenvolvimento das colagens, de apropriação e de escolhas das imagens feitas pelas crianças. Buscamos observar como elas organizavam e selecionavam uma série de imagens, ao ponto de, por si só, elaborar percepções outras, a partir das escolhas das figuras. Novos significados e sentidos foram surgindo em suas experimentações e narrativas que, a partir de pequenos fragmentos, levavam a uma nova criação e (re)elaboração. 

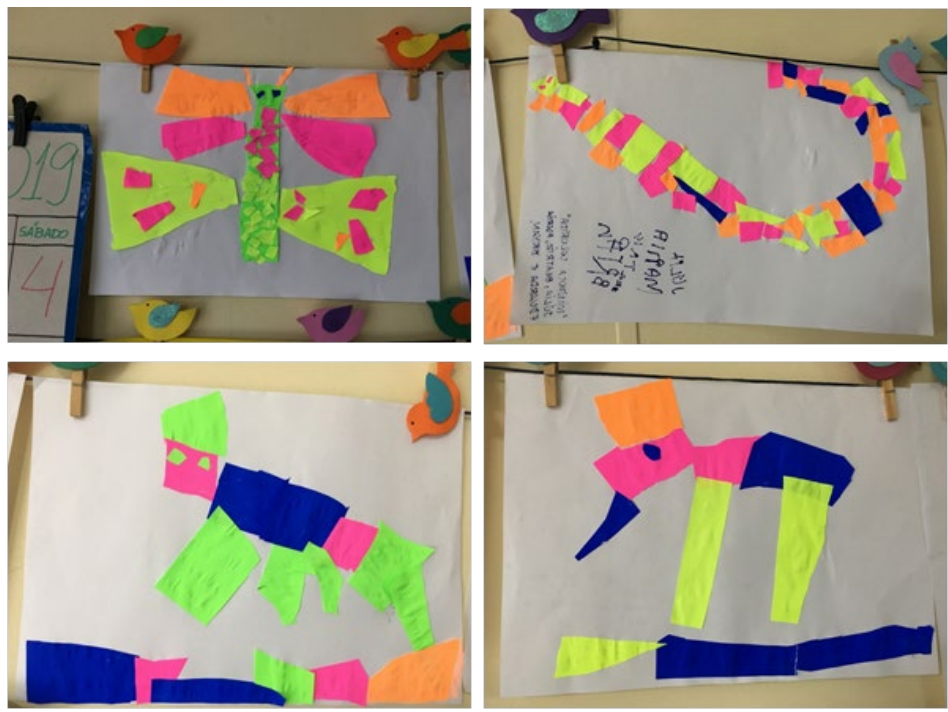

Figura 5, 6, 7 e 8: Criação de bichos com papéis coloridos

Fonte: Acervo pessoal (2019)

As práticas pedagógicas desenvolvidas nos espaços da Educação Infantil nos fazem refletir sobre a maneira como compreendemos os sujeitos que habitam esses espaços. Nesse sentido, defendemos uma ação pedagógica que leve em consideração os saberes das crianças, suas culturas e as diferentes identidades. Por meio de relações dialógicas e alteritárias, estabelecemos com elas modos diversos de apropriação dos conhecimentos construídos historicamente. Seja por meio da arte adulta, da cultura visual, dos instrumentos histórico-culturais, ou de uma arte orgânica e experimental é que vamos construindo essa rede, que aproxima as crianças da vida e da cultura. Nesse sentido, cabe-nos perguntar

[...] como as crianças atuam no campo das investigações e criações artísticas? O que lhes captura o interesse: os processos ou os resultados? Estas são questões importantes e que devem ficar 
mais claras para aqueles que trabalham a Arte na Educação Infantil, para que as instituições educativas acolham as crianças e suas potências inventivas (CUNHA, 2018, p. 238).

Como resposta ao que "Ihes captura o interesse", destacamos os processos criativos resultantes da experimentação autoral com as imagens. As crianças puderam experienciar todo o processo criativamente e o resultado foi mais que a técnica de recorte e colagem, mas um processo discursivo e dialógico que mostra os saberes e as potencialidades de cada uma, que podem ser demonstrados por meio de duas obras: "Macarrãozera" (Figuras 9 e 10) e "Muito colado" (Figuras 11 e 12).


Figura 9 e 10: Recorte e colagem livre - Macarrãozera (Bea)

Fonte: Acervo pessoal (2019). 

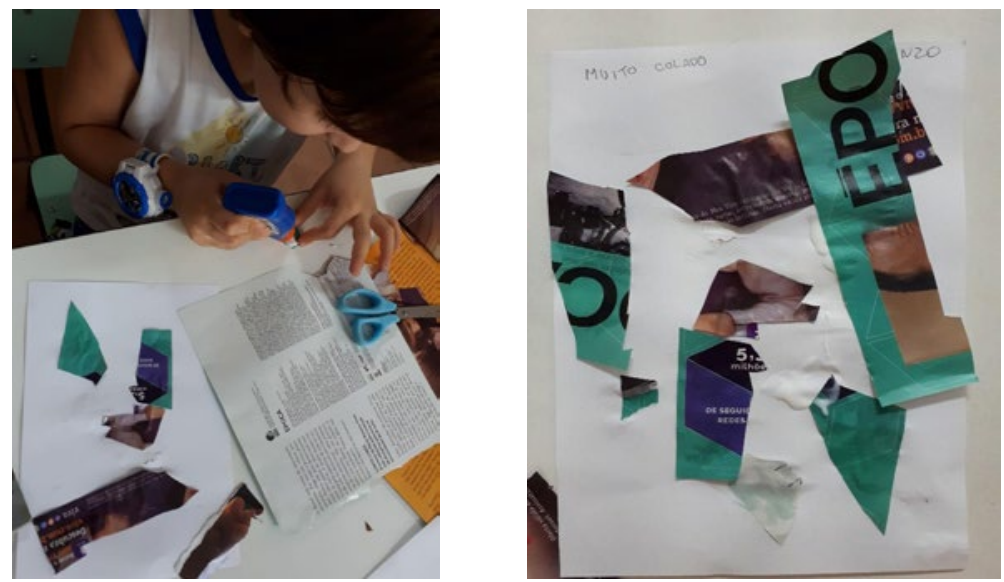

Figura 11 e 12: Recorte e colagem livre - Muito colado (Lo)

Fonte: Acervo pessoal (2019).

Em todas as atividades realizadas as crianças puderam se colocar, interagir, dizer sobre as produções e sobre a satisfação de poder manusear e utilizar os materiais que puderam ter acesso os quais, anteriormente, eram limitados. Ressaltamos que não buscávamos um resultado final; mas, sim, observar como foram se constituindo os processos criativos ao utilizarmos o recorte e colagem como vetores de experiência para a elaboração de novas paisagens, criando um diálogo potente com as crianças que experimentavam diferentes materiais sem serem cerceadas.

\section{CONSIDERAÇÕES FINAIS}

Estimular a criatividade e ações durante a infância, que fazem as crianças produzirem a partir de processos simples, como a técnica da colagem por meio de recortes de mídias impressas, estabelece um diálogo com a realidade dos sujeitos e conexões que os possibilitam criar e combinar sem cerceamento. Não dá para mitigar o potencial criativo das crianças ao lidarem com cola, tesoura e papel ou quaisquer outros materiais. 
Importante destacar que deixar as crianças elaborarem uma produção na qual não haja excesso de monitoria dos adultos, não significa dizer que não haja mediação por parte dos professores. É preciso sempre considerar os desejos e anseios das crianças e não as expectativas dos adultos, para que elas possam criar sem interferências exacerbadas.

Nesse sentido, torna-se possível estimular a imaginação na Educação Infantil por meio das experiências com as Artes Visuais. Diferentemente do que acreditavam os Arte/Educadores modernistas, na contemporaneidade, compreendemos que a criatividade infantil toma por base as experiências dos sujeitos ao se relacionarem com a produção artística dos adultos, pois “[...] os problemas que encontramos hoje no sistema da arte e no sistema da educação, como em outras épocas, refletem-se no diálogo entre a produção das crianças e jovens e a produção sócio-histórica de arte que alcança a contemporaneidade" (IAVELBERG, 2008, p. 1434).

Nessa perspectiva, nossa aposta é fazer com que atividades cotidianas que são vividas na Educação Infantil possam ser fundamentadas na construção histórico-cultural da humanidade. Que essas atividades possam ampliar o universo artístico cultural das crianças, desconstruindo o entendimento de que arte nesse segmento da educação básica seja fundamentado na técnica pela técnica.

Propugnamos, ainda, que ao elaborar as atividades, possamos pensar os instrumentos sem restrições de uso de determinados materiais, mas que eles sejam colocados à disposição das crianças com uma mediação sensível, afetuosa e fundamentada dos educadores presentes. 


\section{REFERÊNCIAS}

ARAÚJO, G. C.; OLIVEIRA, A. A. Sobre Métodos de Leitura de imagem no ensino da arte contemporânea. In: Imagens da Educação. v. 3, n. 2, 2013. p. 70-76.

BARBOSA, M. N. S. Criação, imaginação e expressão da criança: caminhos e possibilidades do desenho infantil. 2018. Disponível em: <https://www.ufsj.edu.br/portal2-repositorio/ File/mestradoeducacao/dissertacao\%20Marina\%20Neves\%20 Silva\%20Barbosa.pdf>. Acesso em: 07/04/2019.

BARBOSA, A. A. T. B. Releitura, citação, apropriação ou o que?. In: BARBOSA, A. M. (org.). Arte/Educação contemporânea: consonâncias internacionais. São Paulo: Cortez, 2005. p. 143149.

CUNHA, S. M. Crianças fazendo Arte: processos de criação artística e formação profissional docente para a Educação Infantil. Unisul, Tubarão: Poiésis, v. 12, n. 21, 2018. p. 235-250, Jan/Jun. Disponível em: <http://www.portaldeperiodicos.unisul. br/index.php/Poiesis/index> Acesso em: 29/06/2019.

IAVELBERG, R. Interações entre a arte das crianças e a produção de arte adulta. Florianópolis: ANPAP, 2008. p. 1425-1436. Disponível em: <http://anpap.org.br/anais/2008/artigos/129. pdf>. Acesso em: 30/04/2019.

KEHRWALD, I. P. Ler e escrever em artes visuais. In: NEVES, I. C. B.; et al (orgs.). Ler e escrever: compromisso de todas as áreas. $7^{\text {a }}$. Ed. Porto Alegre: Editora da UFRGS, 2006, p. 28-29.

MARTINS, Luiz Renato. Colagem: investigações em torno de uma técnica moderna. Revista ARS Arte, Crítica, História da Arte, Resenhas. São Paulo, v. 5, n. 10, 2007. Disponível em: < https://www.scielo.br/scielo.php?script=sci_ arttext\&pid=S1678-53202007000200006 $>$. Acesso em: 20/05/20. 
OSTETTO, L. E. Educação infantil e arte: sentidos e práticas possíveis, 2011. Disponível em: <http://acervodigital.unesp.br/ handle/123456789/320> Acesso em: 10/04/2018.

OSTETTO, L. E. No novelo da memória, atravessamentos do sensível: tornar-se. Revista Digital do LAV. Santa Maria: UFSM, v. 11, n. 2, 2018. p. 166-191.

VIGOTSKI, L. S. A imaginação e a Arte na Infância. Lisboa: Relógio D’Água Editores, 2009. 